\title{
Optimized Hepatocyte-Like Cells with Functional Drug Transporters Directly- Reprogrammed from Mouse Fibroblasts and their Potential in Drug Disposition and Toxicology
}

\author{
Zhi-Tao Wua Dan Yao ${ }^{a}$ Shu-Yi Jib Xuan Nia Yi-Meng Gao ${ }^{b}$ Li-Jian Huib \\ Guo-Yu Pana
}

\begin{abstract}
aShanghai Institute of Materia Medica, Chinese Academy of Sciences, Shanghai, 'Institute of Biochemistry and Cell Biology, Shanghai Institutes for Biological Sciences, Chinese Academy of Sciences, Shanghai, China
\end{abstract}

\section{Key Words}

Direct reprogramming - Hepatocyte-like cells - Hepatic transporters - Biliary clearances • Cholestasis

\begin{abstract}
Background/Aims: To develop a suitable hepatocyte-like cell model that could be a substitute for primary hepatocytes with essential transporter expression and functions. Induced hepatocyte-like (iHep) cells directly reprogrammed from mice fibroblast cells were fully characterized. Methods: Naïve iHep cells were transfected with nuclear hepatocyte factor 4 alpha $(\mathrm{Hnf} 4 \alpha)$ and treated with selected small molecules. Sandwich cultured configuration was applied. The mRNA and protein expression of transporters were determined by Real Time PCR and confocal. The functional transporters were estimated by drug biliary excretion measurement. The inhibition of bile acid efflux transporters by cholestatic drugs were assessed. Results: The expression and function of p-glycoprotein (P-gp), bile salt efflux pump (Bsep), multidrug resistance-associated protein 2 (Mrp2), $\mathrm{Na}^{+}$-dependent taurocholate cotransporting polypeptide (Ntcp), and organic anion transporter polypedtides (Oatps) in iHep cells were significantly improved after transfection of hepatocyte nuclear factor 4 alpha $(\mathrm{Hnf} 4 \alpha)$ and treatment with selected inducers. In vitro intrinsic biliary clearances $\left(\mathrm{CL}_{\mathrm{b} \text {.int }}\right)$ of optimized iHep cells for rosuvastatin, methotrexate, d8-TCA (deuterium-labeled sodium taurocholate acid) and DPDPE ([D-Pen $\left.{ }^{2,5}\right]$ enkephalin hydrate) correlated well with that of sandwich-cultured primary mouse hepatocytes $(\mathrm{SCMHs})\left(r^{2}=0.984\right)$. Cholestatic drugs were evaluated and the results were compared well with primary mice hepatocytes. Conclusion: The optimized iHep cells expressed functional drug transporters and were comparable to primary mice hepatocytes. This study suggested direct reprogramming could provide a potential alternative to primary hepatocytes for drug candidate hepatobiliary disposition and hepatotoxicity screening.

Z.-T. Wu and D. Yao contributed equally to this paper.

Copyright @ 2016 S. Karger AG, Basel

Guo-Yu Pan

Shanghai Institute of Materia Medica, Chinese Academy of Sciences, Haike Road 501,

Shanghai 201203, (China)

Tel. +86-21-20231000-2503, E-Mail gypan@simm.ac.cn
\end{abstract}

KARGER 


\section{Introduction}

The liver is composed mainly of hepatocytes that perform specialized functions, such as biotransformation and elimination of endogenous (e.g., bile acid and lipid) and exogenous compounds (e.g., drugs and toxicants). With high expression and function of drug enzymes and transporters, primary hepatocytes represent a gold standard in vitro model for evaluation of hepatic drug transport, metabolism, clearance and toxicity [1-4]. However, the availability and price of primary hepatocytes have become more scarce and expensive, respectively, which limits their applications. Drug biliary excretion risk and drug-induced cholestasis are two important issues that need to be investigated in the drug discovery phase, and primary hepatocytes are still the best in vitro model because of their essential transporter polarization [5-7]. However, currently, only large pharmaceutical companies can afford such studies during early stages of drug discovery because of the cost and complexity of primary hepatocyte culture.

There have been many efforts to develop a hepatocyte-like cell model with transporter functions, but according to our knowledge, none of these models have been successful. Although the differentiation of embryonic stem (ES) cells or induced pluripotent stem (iPS) cells into hepatocyte-like cells has made remarkable progress recently, no exciting discovery has been reported regarding transporters [8-10]. Global investigations are currently underway to induce direct reprogramming of somatic cells into hepatocyte-like cells as surrogates of primary hepatocytes [11-13]. Our collaborators have demonstrated that it is feasible to directly reprogram mouse fibroblasts (tail-tip fibroblasts, TTFs) into hepatocytelike (iHep) cells using three hepatic transcription factors Gata4, Hnf1 $\alpha$ and Foxa3 [14]. These trans-differentiated iHep cells exhibited typical epithelial morphology, expressed hepatic genes and possessed hepatic functions, which are milestones in developing hepatocyte-like cell models as a potential substitute for primary hepatocytes.

The expression of drug or bile acid transporters, especially their polarization status, has important functional consequences in terms of drug hepatobiliary elimination and drug-induced liver injury, especially in drug-induced cholestasis [5-7]. Compared to other approaches that have been derived to develop hepatocyte-like cell models in vitro or in vivo $[15,16]$, iHep cells showed promising potential in drug development because of their simple generation process and functional drug-metabolizing enzymes. However, we are not sure if it is feasible to utilize iHep cells in the prediction of drug biliary clearance and hepatotoxicity in vitro.

In the present study, we systematically characterized the expression and function of important hepatic transporters in naïve iHep cells and using our novel protocol to develop them exhibiting polarized expression of uptake and efflux transporters. Furthermore, the optimized iHep cells were successful in evaluating biliary excretion risk and drug induced cholestasis of selected compounds. Thus, we propose a potential alternative to primary hepatocytes for drug disposition and toxicity investigation during the early drug discovery phase.

\section{Materials and Methods}

Chemicals and reagents

Fetal bovine serum, insulin, Williams' Medium E, Dulbecco's modified Eagle medium (DMEM) and HBSS (Hanks' balanced salt solution) were obtained from Invitrogen (Carlsbad, CA). ITS ${ }^{\mathrm{TM}}+$ Premix (insulin, transferrin, selenium) and BD Matrige ${ }^{\mathrm{TM}}$ Basement Membrane Matrix were purchased from BD Biosciences (Palo Alto, CA). The taurocholate acid (TCA) and deuterium-labeled sodium taurocholate (d8-TCA) were purchased from GIBCO, Inc. (Grand Island, NY). Dexamethasone and 8-(4-Chlorophenylthio)adenosine 3', $5^{\prime}$-cyclic monophosphate sodium salt (CPT-cAMP) were purchased from Sigma-Aldrich (St. Louis, MO). The cholyl-lysyl-fluorescein (CLF) and 5-(and-6)-carboxy-2', 7'-dichloro-fluorescein (CDF) were purchased from BD Biosciences (Palo Alto, CA). [D-Pen ${ }^{2,5}$-enkephalin (DPDPE) was purchased from Tocris Bioscience

\section{KARGER}




\section{Cellular Physiology Cell Physiol Biochem 2016;38:1815-1830 \begin{tabular}{l|l|l} 
DOI: 10.1159/000443120 & (C) 2016 S. Karger AG, Basel
\end{tabular} and Biochemistry Published online: May 09, $2016 \quad$ www.karger.com/cpb \\ Wu et al.: Optimized Hepatocyte-Like Cells from Mouse Fibroblasts}

(Ellisville, MO). All other chemicals and reagents were of analytical grade and were readily available from commercial sources.

Animals

ICR (Institute of Cancer Research) mice were obtained from Shanghai Laboratory Animal Center Co., Ltd. (Shanghai, China). Mice were maintained on a 12-h light/dark cycle with free access to water and standard rodent chow. This study was conducted in strict accordance with the recommendations in the Guide for the Care and Use of Laboratory Animals of the Association for Assessment and Accreditation of Laboratory Animal Care International (AAALAC). The animal use protocol was approved by the Institutional Animal Care and Use Committee (IACUC) of Shanghai Institute of Materia Medica (SIMM).

\section{Primary mouse hepatocyte isolation and culture}

Primary mouse hepatocytes were isolated from an ICR male mouse (25 g) using a previously described two-step collagenase perfusion method [17]. Primary hepatocytes were plated on 24-well BioCoat plates with collagen type I substratum (BD Biosciences, CA, USA). The hepatocytes were overlaid with $0.25 \mathrm{mg} / \mathrm{mL}$ Matrigel Basement Membrane Matrix $24 \mathrm{~h}$ after seeding to form a sandwich configuration and were cultured as described previously with minor modifications $[18,19]$. The sandwich-cultured mouse hepatocytes $(\mathrm{SCMH})$ were used for study within 4 days after isolation.

\section{iHep cell culture}

Naïve iHep cells were kindly supplied by Professor Lijian Hui. The cells were generated and cultured using standard conditions as described by Huang et al. [14]. Briefly, tail-tip fibroblast (TTF) cells provided by Lijian Hui's lab (Shanghai, China) were seeded onto a $60-\mathrm{mm}$ collagen-I-coated dish and transfected with three transcription factors, Gata4, Hnf1 $\alpha$ and Foxa3, according to Huang's protocol. The cells were then cultured in Block's medium containing $0.1 \mu \mathrm{M}$ dexamethasone, $20 \mu \mathrm{g} / \mathrm{L}$ transforming growth factor alpha (TGF- $\alpha$ ), $10 \mu \mathrm{g} / \mathrm{L}$ epidermal growth factor (EGF), $4.2 \mathrm{mg} / \mathrm{L}$ insulin, $3.8 \mathrm{mg} / \mathrm{L}$ human transferrin, and $5 \mathrm{mg} / \mathrm{L}$ sodium selenite at $37^{\circ} \mathrm{C}$ in a humidified atmosphere with $5 \% \mathrm{CO}_{2}$. It took approximately 6 days for iHep cells to form the monolayers used in the following studies. The cells were named as naïve iHep cells before being optimized. The bile canaliculi formation of hepatocyte morphology was assessed by CDF accumulation followed by phase-contrast microscopy and fluorescence microscopy using a Nikon TE-2000U microscope (Nikon, Melville, NY) and an EXi digital CCD camera (QImaging, Burnaby, BC, Canada).

For optimization purposes, naïve iHep cells were seeded onto a 60-mm collagen I-coated dish and infected with lentiviruses carrying indicated genes (Hnf $4 \alpha$, GenBank accession no. NM_008261) and treated with different small molecules for $72 \mathrm{~h}$. The optimized iHep cells were refered to the cells transfected with Hnf $4 \alpha$ and cultured with medium containing small molecules.

\section{RNA isolation and real-time reverse transcription PCR (RT-PCR)}

Total RNA was extracted (SV Total Isolation System, Promega, Madison, WI, USA), and cDNA synthesis was performed from $2 \mu \mathrm{g}$ reverse transcriptions of mRNA. Specific primers were designed from GenBank mouse mRNA sequences (Table 1). RT-PCR was performed using a PE Biosystems ABI Prism 7500 Sequence

Table 1. Primer sequences used for RT-PCR

\begin{tabular}{llll}
\hline Gene & Accession number & Forward Primer (5'-3') & Reverse Primer (5'-3') \\
\hline Mdr1a/Abcb1a & NM_011076.2 & CAGCAGTCAGTGTGCTTACAA & ATGGCTCTTTTATCGGCCTCA \\
Bcrp/Abcg2 & NM_011920.3 & AAATGGAGCACCTCAACCTG & CCCATCACAACGTCATCTTG \\
Mrp1/Abcc1 & NM_008576.3 & TGATGGCTCCGATCCACTCT & TCCACAGAAAGAATCCTAAGGCA \\
Mrp2/Abcc2 & NM_013806.2 & GTGTGGATTCCCTTGGGCTTT & CACAACGAACACCTGCTTGG \\
Bsep/Abcc11 & NM_021022.3 & TCTGACTCAGTGATTCTTCGCA & CCCATAAACATCAGCCAGTTGT \\
Nctp/Slc10a1 & NM_001177561.1 & ATGGAGGCGCACAACGTATC & ACTACCAGAATGACGCTGAGC \\
Oatp1a1 & NM_013797.5 & GTGCATACCTAGCCAAATCACT & CCAGGCCCATAACCACACATC \\
Oatp1b2 & NM_020495.1 & CCTGAGAAGTGTCCGCATAAC & GTCCGAGTGGCAGTAAGAAAG \\
Oatp1a4 & NM_030687.1 & GCTTTTCCAAGATCAAGGCATTT & CGTGGGGATACCGAATTGTCT \\
Pxr & AF031814.1 & GATGGAGGTCTTCAAATCTGCC & GGCCCTTCTGAAAAACCCCT \\
Fxr & NT_039500.8 & GCTTGATGTGCTACAAAAGCTG & CGTGGTGATGGTTGAATGTCC \\
Car & AF009326.1 & ATATGGGCCGAGGAACTGTGT & GGCGTGGAAATGATAGCCTGT \\
Nrf2 & U70475.1 & TCTTGGAGTAAGTCGAGAAGTGT & GTTGAAACTGAGCGAAAAAGGC \\
B-actin & NM_007393.3 & GGCTGTATTCCCCTCCATCG & CCAGTTGGTAACAATGCCATGT \\
\hline
\end{tabular}




\section{Cellular Physiology Cell Physiol Biochem 2016;38:1815-1830 \begin{tabular}{ll|l} 
and Biochemistry $10.1159 / 000443120$ & Published online: May 09, 2016 & $\begin{array}{l}\text { O 2016 S. Karger AG, Basel } \\
\text { www.karger.com/cpb }\end{array}$ \\
\cline { 2 - 3 }
\end{tabular} \\ Wu et al.: Optimized Hepatocyte-Like Cells from Mouse Fibroblasts}

Detection System and the RT-PCR Core kit for SYBR Green. Data were analyzed using PE Biosystems ABI Prism 7500 Sequence Detector software. $\beta$-actin was employed as the housekeeping gene.

\section{Western blotting}

The total protein of hepatocytes was extracted by RIPAlysis buffer containing $1 \mathrm{mM}$ phenylmethylsulfonyl fluoride (Beyotime, Haimen, China). The proteins were separated by 10\% SDS-PAGE. After transferring the proteins to a polyvinylidene difluoride membrane, the membrane was blocked, incubated with primary antibodies overnight at $4^{\circ} \mathrm{C}$ : the specific primary antibodies against Hnf4 $\alpha$ (mouse monoclonal; 1:500; Santa Cruz Biotechnology, CA, USA), against P-gp (rabbit monoclonal; 1:1000; Abcam, MA, USA), against Oatp2 (mouse monoclonal; 1:200; Santa Cruz Biotechnology, CA, USA), against Pxr (rabbit polyclonal 1:200; Santa Cruz Biotechnology, CA, USA), against Fxr (rabbit polyclonal 1:200; Santa Cruz Biotechnology, CA, USA) and against Nrf2 (rabbit polyclonal; 1:200; Santa Cruz Biotechnology, CA, USA) were used in western blotting. The immunoblots were then incubated with a secondary antibody conjugated with horseradish peroxidase for $1 \mathrm{~h}$ at room temperature. $\beta$-actin (monoclonal; 1:5000; Sigma, MO, USA) was selected as the internal control. The membranes were developed using an electrochemiluminescence (ECL) kit (Thermo Scientific/Pierce, Rockford, IL, USA) according to the manufacturer's protocol. The optical density of the bands was measured and quantified by Image J (National Institute of Health, MD, USA).

\section{Confocal laser scanning microscopy}

Cells were fixed directly in glass cover slips at room temperature for $1 \mathrm{~h}$ with $4 \%$ (w/v) paraformaldehyde in phosphate-buffered saline (PBS) and processed as previously described [20].

For co-localization of bile salt export pump (Bsep) and multidrug resistance protein 2 (Mrp2), monoclonal antibody H-180 (mouse anti-Bsep, Santa Cruz; 1:100) and polyclonal antibody (rabbit antiMrp2, Santa Cruz; 1:40) in PBS supplemented with 1\% BSA were applied for $16 \mathrm{~h}$ in a wet chamber. PBS/ BSA alone and a single primary antibody were used for control staining. After being rinsed and washed, the cover slips were incubated for $1 \mathrm{~h}$ with a secondary antibody mixture consisting of tetramethylrhodamine (TRITC) anti-rabbit IgG (Jackson Laboratories, 1:400) and fluorescein isothiocyanate (FITC) anti-mouse IgG (Jackson Lab, 1:300) in PBS with 1\% BSA. After a final washing step, the slides were covered with mounting medium (1,4-diazabicyclo[2.2.2] octane [2.5\%]) in glycerol/PBS (9:1). The cells were observed by confocal laser-scanning microscopy using the Leica TCS 4D microscope (Leica, Wetzlar, Germany) equipped with an argon/krypton laser. Double-labeled images were taken sequentially at 488 and $519 \mathrm{~nm}$. For p-glycoprotein (P-gp) and breast cancer resistance protein (Bcrp) staining, the same procedure was used with monoclonal antibody E-10 (mouse anti-P-gp, ABCAM; 1:200) and a polyclonal antibody (rabbit anti-Bcrp, ABCAM; $1: 100)$.

\section{Drug biliary excretion measurement}

Different drug substrates of efflux transporters were used for evaluating hepatic biliary excretion in iHep cells. Accumulation studies were conducted based on a modified version of reported protocols using B-CLEAR ${ }^{\circledR}$ technology [21, 22]. Briefly, iHep cells cultured on 24-well BioCoat plates were rinsed two times with $300 \mu \mathrm{L}$ per well of warmed HBSS with $\mathrm{Ca}^{2+}$ (standard buffer) or without $\mathrm{Ca}^{2+}$. After washing, $0.5 \mathrm{~mL}$ of standard HBSS or $\mathrm{Ca}^{2+}$-free HBSS was added, and cells were incubated at $37^{\circ} \mathrm{C}$ for $15 \mathrm{~min}$. Then, the solution was aspirated from each well and incubated with $300 \mu \mathrm{L}$ standard HBSS-containing substrate $(2.5$ $\mu \mathrm{M}$ rosuvastatin, $2.5 \mu \mathrm{M}$ methotrexate, $2.5 \mu \mathrm{M}$ CLF or $2.5 \mu \mathrm{M}$ DPDPE or $2.5 \mu \mathrm{M}$ d8-TCA) at $37^{\circ} \mathrm{C}$ for $10 \mathrm{~min}$. After incubation, the solution was discarded, and cells were rinsed three times with ice-cold PBS. The plates were stored at $-80^{\circ} \mathrm{C}$ until analysis.

\section{Measurement of bile acid transport inhibition in iHep cells}

Several drugs inducing cholestasis were selected as Bsep inhibitors. The assay was performed according to a previous study [23]. Briefly, cells were rinsed two times with $300 \mu \mathrm{L}$ of warm standard HBSS or $\mathrm{Ca}^{2+}$-free HBSS and pre-incubated with $300 \mu \mathrm{L}$ of the same buffer with or without inhibitors at $37^{\circ} \mathrm{C}$ for $15 \mathrm{~min}$. After removing the buffer, hepatocytes were incubated for $15 \mathrm{~min}$ with d8-TCA $(2.5 \mu \mathrm{M})+$ different inhibitors in $300 \mu \mathrm{L}$ of standard HBSS. After incubation, the solution was aspirated from the cells, uptake was terminated by washing three times with ice-cold PBS, and the samples were frozen for analysis. The biliary excretion index (BEI) of d8-TCA was calculated as described below. 


\section{Cellular Physiology Cell Physiol Biochem 2016;38:1815-1830 \begin{tabular}{ll|l} 
and Biochemistry $10.1159 / 000443120$ & Published online: May 09, 2016 & $\begin{array}{l}\text { C 2016 S. Karger AG, Basel } \\
\text { www.karger.com/cpb }\end{array}$ \\
\hline
\end{tabular} \\ Wu et al.: Optimized Hepatocyte-Like Cells from Mouse Fibroblasts}

Liquid chromatography-tandem mass spectrometry (LC-MS/MS) conditions

The analytical column effluent of each sample was directly introduced into LC/MS/MS, which consisted of an Agilent 1100 HPLC system (Agilent Technologies, Waldbronn, Germany) and an API 4000 MS/MS system (Applied Biosystems/MDS SCIEX, Concord, Ontario, Canada), using electrospray ionization in a positive ion scanning mode. Chromatographic separation was achieved using a mobile phase of acetonitrile:1 $\mathrm{mM}$ ammonium formate containing $0.1 \%$ formic acid and delivered at a flow rate of $0.2 \mathrm{~mL} / \mathrm{min}$ through a guard cartridge (C18, $4.0 \times 2.0 \mathrm{~mm}$, Phenomenex, Torrance, CA) and an analytical column (Phenomenex, Luna $3 \mathrm{u} \mathrm{C18} \mathrm{(2)} 100 \mathrm{~A}, 3 \mu \mathrm{m}$ particle size, $50 \times 2.0 \mathrm{~mm}$ ). The column temperature was maintained at $35^{\circ} \mathrm{C}$. Selected reaction monitoring was used to simultaneously monitor for analytes and the internal standard. The following selected reaction-monitoring transitions were used for analyte detection: $\mathrm{m} / \mathrm{z} 522.1 \rightarrow 128.0$ for d8-TCA, m/z $482.0 \rightarrow 258.0$ for rosuvastatin, $\mathrm{m} / \mathrm{z} 455.1 \rightarrow 308.3$ for methotrexate, and $\mathrm{m} / \mathrm{z} 552.0 \rightarrow$ 279.0 for the internal standard (bosentan), with a dwelling time of $800 \mathrm{~ms}$ for each channel. The ion spray voltage was set at $3500 \mathrm{~V}$, and the temperature was set at $550^{\circ} \mathrm{C}$. The collision energies for collision-induced dissociation for the aforementioned transitions were set to be 40, 25, and 27 for rosuvastatin, d8-TCA and methotrexate, respectively.

Data analysis

Calculation of $\mathrm{BEI}$ and in vitro intrinsic biliary clearance (in vitro $\mathrm{CL}_{\mathrm{b}, \mathrm{int}}$ ) in this report are similar to that performed by Liu et al. [24]. BEI is determined over a 10-min interval using the equation below.

$$
\mathrm{BEI}=\frac{\mathrm{A}_{\text {plus_Ca++ }}-\mathrm{A}_{\text {minus_Ca++ }}}{\mathrm{A}_{\text {plus_Ca++ }}} \times 100 \%
$$

Where $\mathrm{A}$ is the test compound accumulation amount in wells of SCMHs in 24-well plates (pM/well), $A_{\text {plus }}$ $\mathrm{Ca}++_{+}$represents the test compound accumulation amount in standard buffer-treatment wells, and $\mathrm{A}_{\text {minus_ca++ }}$ represents the test compound accumulation amount in the $\mathrm{Ca}^{2+}$-free buffer-treatment wells. The value calculated in Eq. (1) represents the percentage of the initial drug concentration excreted into the bile.

$$
\text { in vitro } C L_{b, \text { int }}=\frac{\mathrm{A}_{\text {plus_Ca }++}-\mathrm{A}_{\text {minum_Ca }++}}{\mathrm{AUC}_{0-10 \mathrm{~min}}}
$$

In Eq. (2), in vitro $\mathrm{CL}_{\mathrm{b}, \text { int }}$ represents the biliary excretion of the tested compound. Here, the total concentration of the test compound during the entire incubation time was quantified using the area under the curve AUC $_{0-}$ 10min $)\left(\mathrm{AUC}_{0-10 \min }=\right.$ time $\left.\times\left(\mathrm{C}_{\mathrm{m}, 0 \min }+\mathrm{C}_{\mathrm{m}, 10 \min }\right) / 2\right) . \mathrm{C}_{\mathrm{m}, 0 \min }$ and $\mathrm{C}_{\mathrm{m}, 10 \min }$ represent the substrate concentrations at the beginning ( $0 \mathrm{~min}$ ) and end of the incubation period (10 $\mathrm{min})$, respectively.

\section{Statistical analysis}

Results are expressed as means \pm standard deviations. Statistical analysis was performed using GraphPad Prism 5.03 software. Differences between the two groups were analyzed using Student's $t$-test. One-way analysis of variance (ANOVA) and Tukey's multiple comparison test were used to test for statistical significance among groups. Differences were considered significant at $p<0.05$.

\section{Results}

Characterization of transporters in iHep cells

Hepatic drug transporter expression levels in naïve iHep cells were analyzed using RT-PCR. The investigated genes were P-gp, Bsep, Mrp2, Bcrp, sodium/taurocholate cotransporting polypeptide (Ntcp), organic-anion transporting polypeptides (Oatp) 1b2, Oatp1a1, and Oatp1a4. All expression values were compared with those measured in SCMHs and TTFs. Hepatic transporter expression was detectable in naïve iHep cells but was much lower than that in SCMHs. None of the measured mRNA levels was higher than 20\% of SCMHs. In TTFs, expression of the selected transporters was not detected (Fig. 1A). Protein levels of P-gp and Mrp2 in iHep cells were checked by confocal microscopy. Both proteins were detected in the canalicular membranes of SCMHs. However, the proteins were not polarized in the canalicular membranes of naïve iHep cells (Fig. 1B). The bile canaliculi in hepatocytes 
Fig. 1. Characterization of naïve iHep cell transporters. (A) mRNA expression levels of transporters in TTF, SCMH and naïve iHep cells were analyzed using RT-PCR. (B) Representative confocal images of P-gp (green) and Mrp2 (red) in iHep cells and SCMHs are shown. Co-localization is indicated in yellow. (C) The results of CDF accumulation in bile canaliculi formed in SCMHs (left) and naïve iHep cells (right). Cells were incubated with CDF (5 $\mu \mathrm{M})$ for 10 $\min$ at $37^{\circ} \mathrm{C}$. (D) BEI deter-

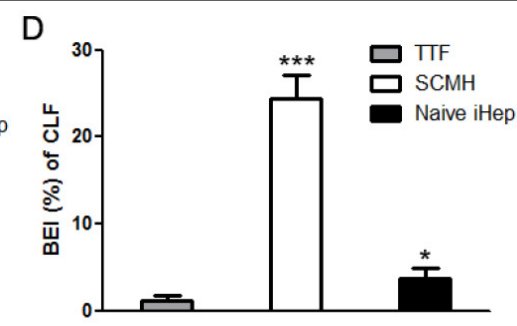

B
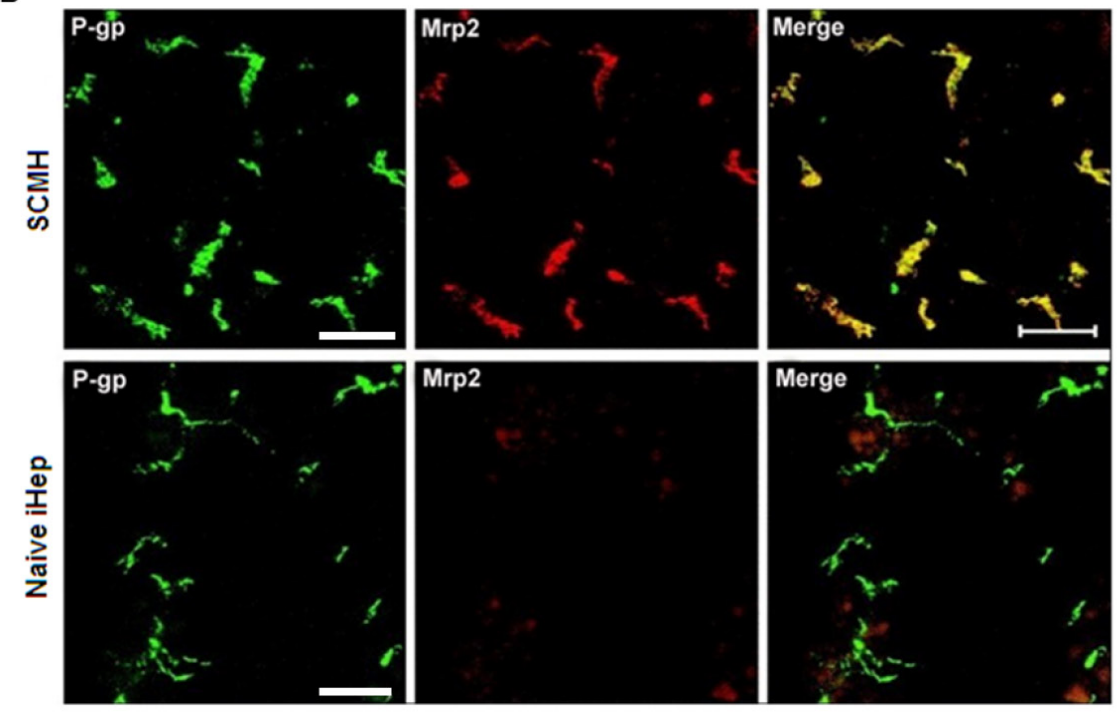

C $\mathrm{SCMH}$

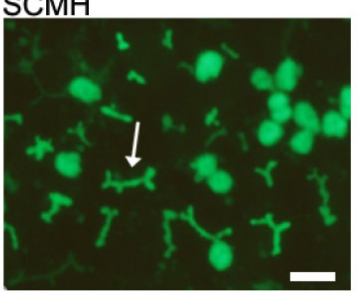

Naive iHep

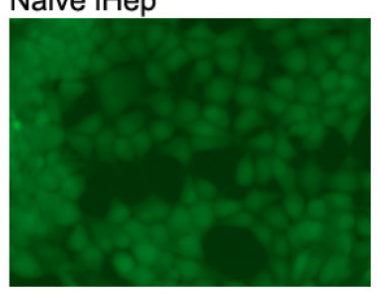

minations of CLF $(2.5 \mu \mathrm{M})$ in TTF, SCMH and naïve iHep cells. Scale bars, $50 \mu \mathrm{m}$. Data are the means \pm SD of three independent experiments. ${ }^{*} \mathrm{P}<0.05{ }^{* *} \mathrm{P}<0.01$, and ${ }^{* * *} \mathrm{P}<0.001$ compared with TTF cells.

were characterized by the uptake and excretion of fluorescence substrate CDFs in SCMHs and naïve iHep cells on day 6 of culture. Sharp boundary fluorescent areas (bile pockets) between cultured primary hepatocytes were observed by fluorescent microscopy, but not in naïve iHep cells (Fig. 1C).

The transporter function was evaluated by calculating the BEI value of CLF. The BEI values of CLF in SCMHs were greater than 25\%, indicating significant biliary excretion. In contrast, the BEI values in iHep cells were less than $5 \%$, suggesting weak transporter polarization and function in naïve iHep cells (Fig. 1D).

Induction of transporters and hepatic nuclear receptors in iHep cells by Hnf4 $\alpha$ transduction

After transfection of $\mathrm{Hnf} 4 \alpha$ into naïve iHep cells through lentiviruses (Fig. 2A), the mRNA expression levels of efflux and uptake drug transporters (P-gp, Bsep, Mrp2, Bcrp; Ntcp, Oatp1b2,Oatp1a1, Oatp1a4) were significantly increased 2-5-fold (Fig. 2B). Hepatic nuclear receptors, such as pregnane $\mathrm{X}$ receptor (Pxr), farnesoid X receptor (Fxr), constitutive androstane receptor (Car), and transcription factor NFE2-related factor-2 (Nrf2) in naïve

\section{KARGER}


Fig. 2. Effects of Hnf $4 \alpha$-transduction on transporter and nuclear receptor expression in iHep cells. After Hnf $4 \alpha$ transfection (A), the relative mRNA expression levels of efflux and uptake transporters (B) and nuclear receptors $(C)$ were determined by RT-PCR. The morphology of iHep cells were shown after Hnf4 $\alpha$ transfection (D). Scale bars, $50 \mu \mathrm{m}$. Data are the means \pm SD of three independent experiments. ${ }^{*} \mathrm{P}<0.05$, ** $\mathrm{P}<0.01$, and ${ }^{* * *} \mathrm{P}<0.001$ compared with naïve iHep cells.

Table 2. Nuclear receptor inducers used for iHep optimization. a. Peroxisome proliferator-activated receptor alpha

\begin{tabular}{lll}
\hline Compound & Concentration & Target \\
\hline cAMP & $5 \mu \mathrm{M}$ & PKA pathway \\
3 -MC & $2 \mu \mathrm{M}$ & Pxr,Ahr \\
PB & $50 \mu \mathrm{M}$ & Car \\
TCA & $20 \mu \mathrm{M}$ & Fxr \\
VPA & $1 \mathrm{mM}$ & PPAR $\alpha$ a, Pxr \\
\hline
\end{tabular}

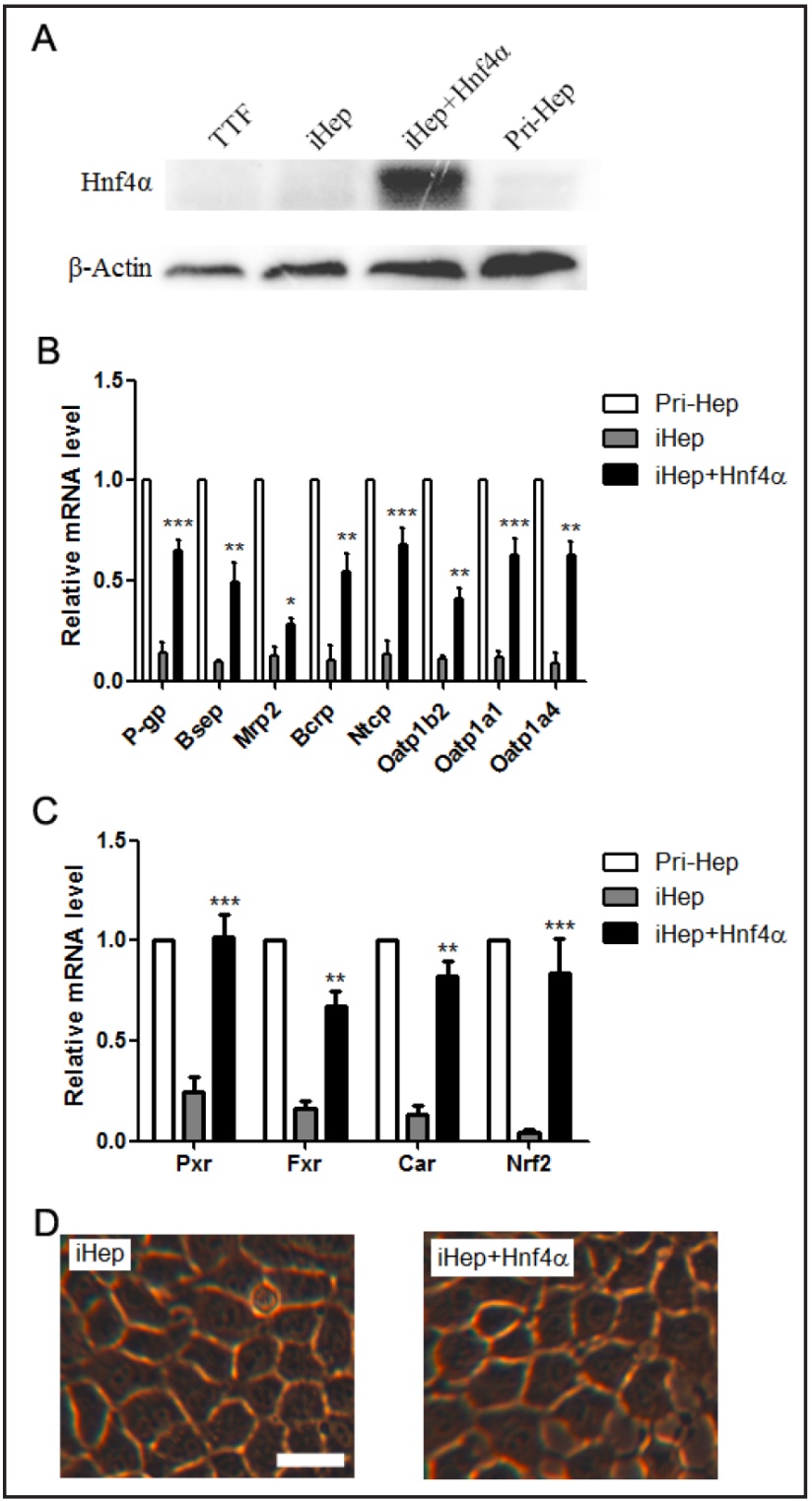

iHep cells were determined by RT-PCR. As shown in Fig. 2C, the Pxr, Fxr, Car and Nrf expression levels were increased 4.0- to 8.0-fold after Hnf4 $\alpha$ transfection treatment in iHep cells. When compared with naïve iHeps, the morphology of iHep cells had no change after overexpression of $\mathrm{Hnf} 4 \alpha$ (Fig. 2D).

Induction of transporter and hepatic nuclear receptor $m R N A$ expression in iHep cells after small molecule treatment

Different nuclear receptor inducers were chosen to activate related functions in naïve iHep cells. The compounds with defined concentration and their respective nuclear receptors are summarized in Table 2. As shown in Fig. 3A-D, CPT-cAMP (cAMP), phenobarbital (PB), and TCA significantly increased mRNA expression levels of the above transporters, especially hepatic bile acid transporters Bsep, Mrp2 and Ntcp after $72 \mathrm{~h}$ of treatment. 3methylcholanthrene (3-MC) had almost no impact on most of the selected transporter expression levels, and valproic acid (VPA) could slightly improve Bsep, Mrp2, Oatp1a1, and Oatp1a4 expression (Fig. 3A-D; Fig. 4A-D). The mRNA levels of these nuclear receptors in iHep cells treated with cAMP, PB and TCA for $72 \mathrm{~h}$ were significantly increased, especially 
Fig. 3. Small molecules induced the expression of efflux transporters in iHep cells. The relative mRNA expression levels of selected efflux transporters P-gp (A), Bsep (B), Mrp2 (C) and Bcrp (D) in iHep cells were determined by RT-PCR after treatment with small molecules for $72 \mathrm{~h}$. Data are normalized to $\beta$-actin mRNA and presented as the means \pm SD of three independent experiments. ${ }^{*} \mathrm{P}<0.05$, ** $\mathrm{P}<$ 0.01 , and $* * * \mathrm{P}<0.001$ compared with naïve iHep cells.

Fig. 4. Small molecules induced the expression of uptake transporters in iHep cells. The relative mRNA expression levels of selected uptake transporters Ntcp (A), Oatp1b2 (B), Oatp1a1 (C) and Oatp1a4 (D) in iHep cells were determined by RT-PCR after treatment with small molecules for 72 h. Data are normalized to $\beta$-actin mRNA and presented as the means \pm SD of three independent experiments. ${ }^{*} \mathrm{P}<$ 0.05 , ** $\mathrm{P}<0.01$, and $* * *$ $\mathrm{P}<0.001$ compared to naïve iHep cells.
A

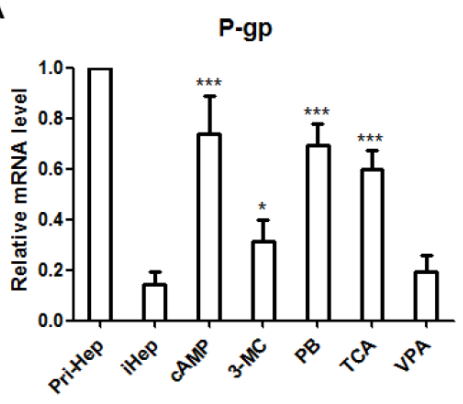

C

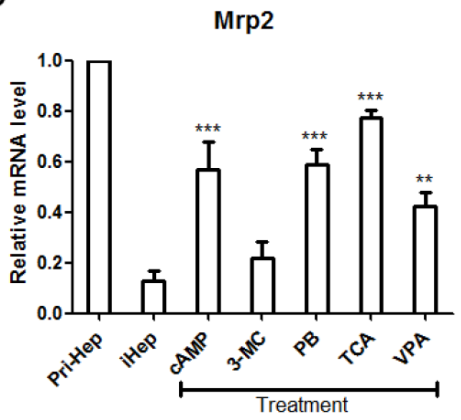

B

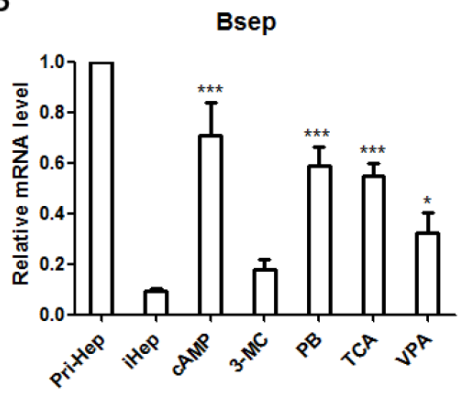

D

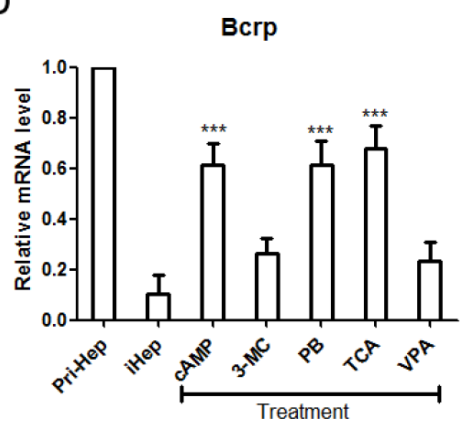

A

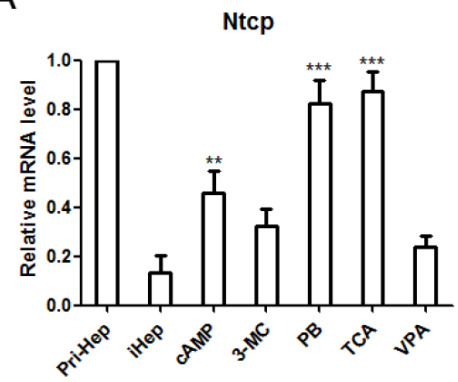

C

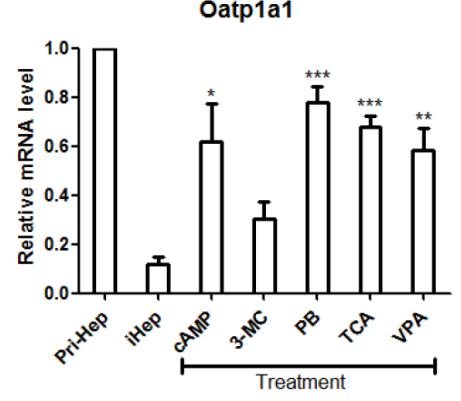

B

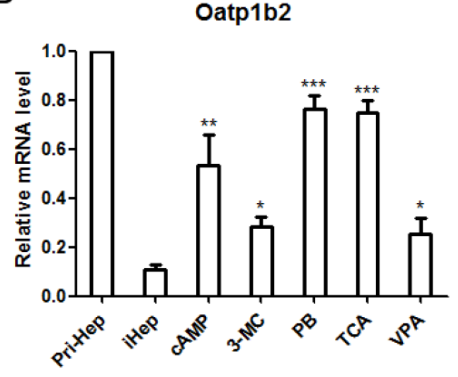

D

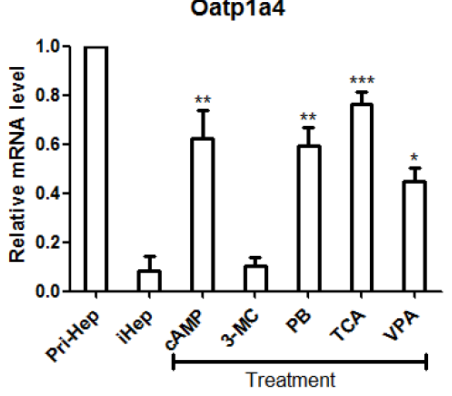

for Pxr and Car (Fig. 5A-C). Similarly, transcription factor Nrf2 mRNA expression was also elevated (Fig. 5D).

Changes in culture conditions, such as to sandwich culture configurations and serum-free and long-term cultures ( 6 weeks), also ameliorated hepatic transporter mRNA expression in iHep cells (data not shown). 
Fig. 5. Effects of small molecules on the expression of nuclear receptors and transcription factors in iHep cells. The relative mRNA expression levels of nuclear receptors Pxr (A), Fxr (B), Car (C) and transcription factor Nrf2 (D) in iHep cells were determined by RT-PCR after treatment with cAMP $(2 \mu \mathrm{M})$, PB $(50 \mu \mathrm{M})$ and TCA $(20 \mu \mathrm{M})$ for 72 h. Data are normalized to $\beta$-actin mRNA and presented as the means \pm SD of three independent experiments. The protein expression of P-gp, Oatp2,

A

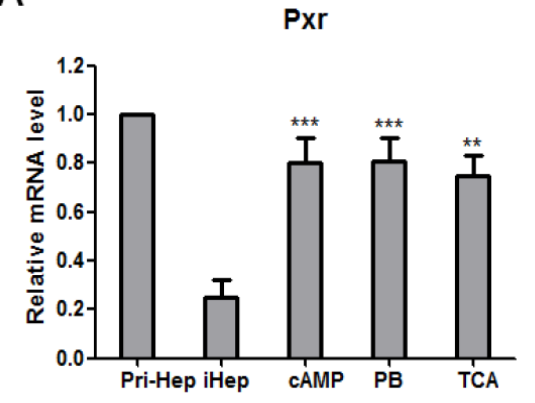

C

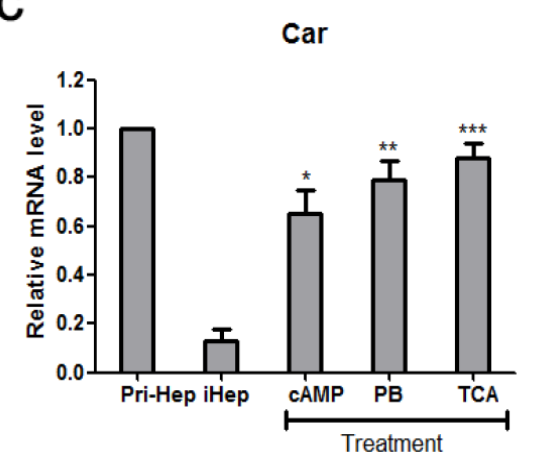

B

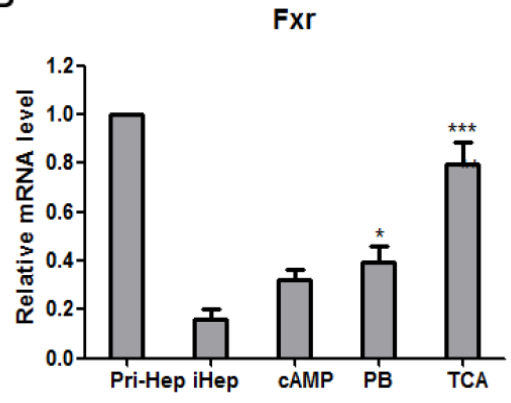

$\mathrm{D}$

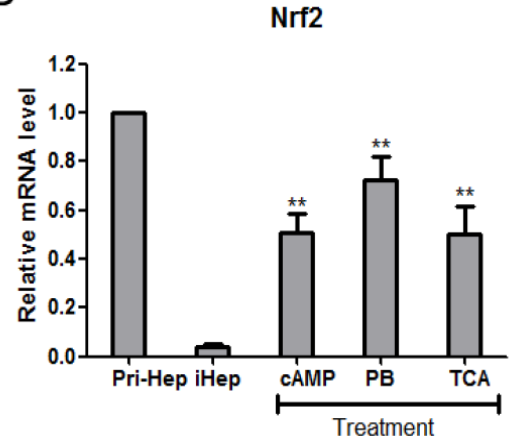

E
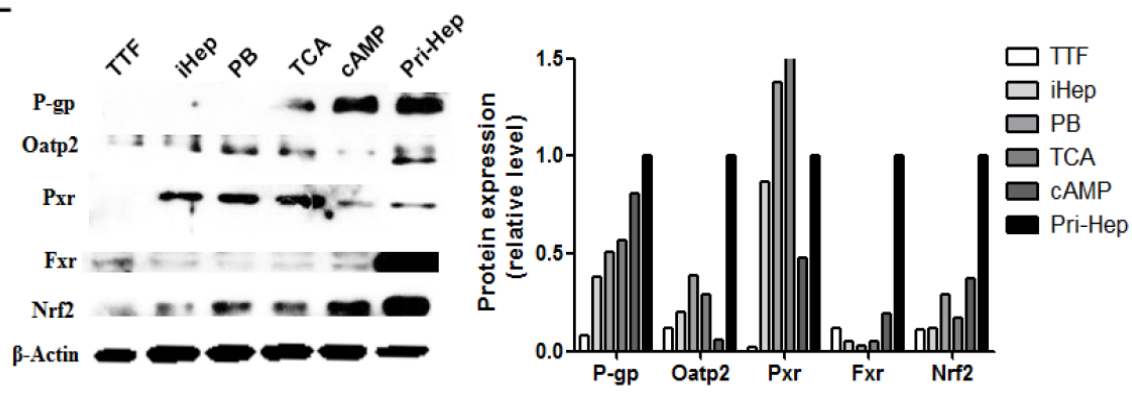

Pxr, Fxr, and

Nrf2 in iHep cells was determined by western blotting after the same treatments (E). The density values were normalized for $\beta$-actin. The western blotting experiment was repeated and the same trend was observed. $* \mathrm{P}<0.05$, ${ }^{* *} \mathrm{P}<0.01$, and ${ }^{* * *} \mathrm{P}<0.001$ compared to naïve iHep cells.

\section{Protein expression of transporter and hepatic nuclear receptor after treatment}

Western blotting was carried out to determine protein expressions of the transporter and hepatic nuclear receptors. As shown in Fig. 5E, the protein expression levels of P-gp and Nrf2 were both increased after $72 \mathrm{~h}$ incubation with PB or TCA or cAMP. Besides, after treatment with PB or TCA for $72 \mathrm{~h}$, the protein levels of Oatp2 and Pxr in iHep cells were slightly increased. But the Fxr expression was not influenced by the above treatment.

\section{BEI determination of transporter substrates in naïve iHep cells}

CLF and rosuvastatin were selected as the substrates of efflux transporters to determine the function of transporters in iHep cells after treatment. The BEI values of CLF in iHep cells were induced 1.9- and 2.1-fold by cAMP and TCA, respectively (Fig. 6A). Rosuvastatin was mainly transported by Bcrp, and its BEI increased by 1.4- and 1.7-fold, respectively (Fig. 6B). 


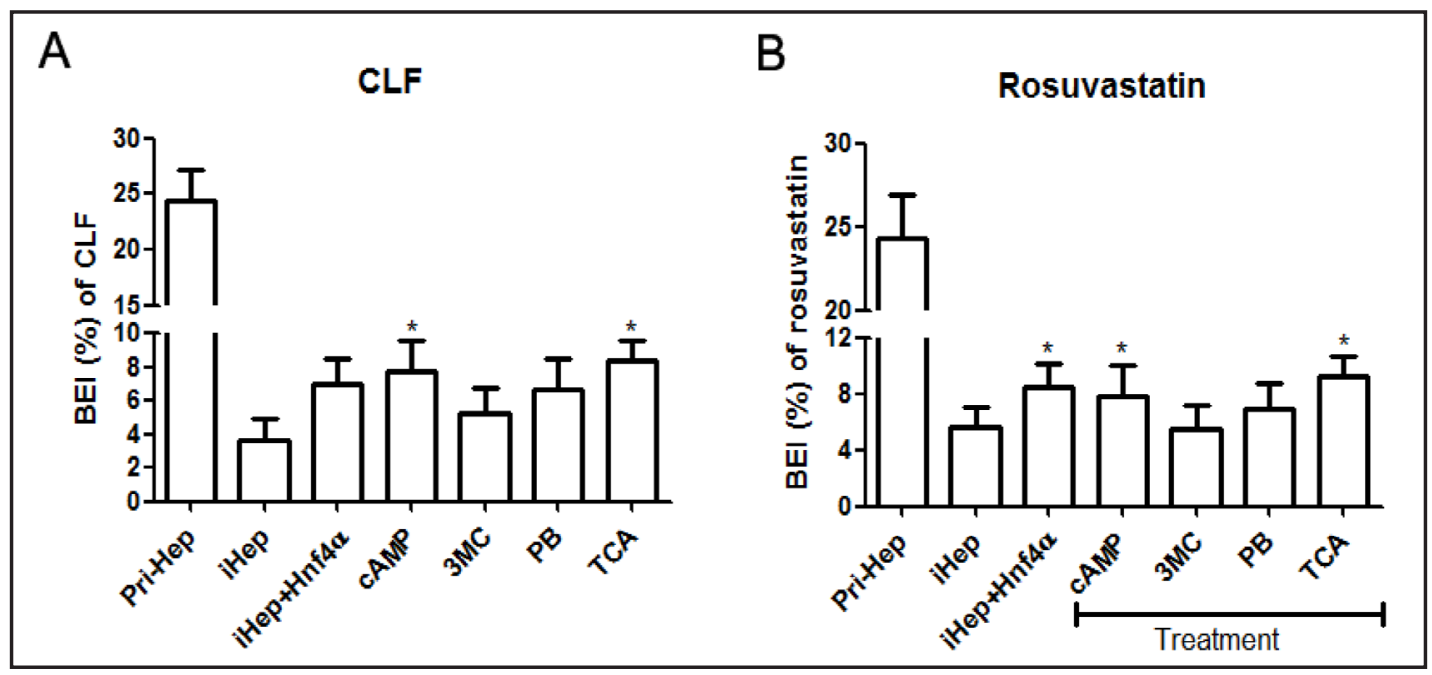

Fig. 6. Determination of transporter function after $\mathrm{Hnf} 4 \alpha$-transduction and small molecule treatment in iHep cells. Cells were incubated with CLF $(2.5 \mu \mathrm{mol} / \mathrm{L})$ or rosuvastatin $(2.5 \mu \mathrm{mol} / \mathrm{L})$ after treatment, and the BEI values of CLF (A) and rosuvastatin (B) were determined. The BEI indicates the efflux capacity of transporters. Data are the means $\pm \mathrm{SD}$ of three independent experiments. $* \mathrm{P}<0.05,{ }^{* *} \mathrm{P}<0.01$, and ${ }^{* * *} \mathrm{P}<$ 0.001 compared to naïve iHep cells.

\section{Expression and activity of drug transporters in optimized iHep cells}

Based on the above study results, a novel optimization protocol was generated, and the optimized iHep cells were characterized. The naïve iHep cells were transfected with Hnf $4 \alpha$ and then cultured with serum-free medium containing $5 \mu \mathrm{M}$ cAMP, $50 \mu \mathrm{M} \mathrm{PB}$, and $20 \mu \mathrm{M}$ TCA in sandwich configuration. Among the basolateral and canaliculi transport systems, the expression levels of the efflux transporters (P-gp, Mrp2, Bsep and Bcrp) and uptake transporters (Ntcp, Oatp1b2, Oatp1a1 and Oatp1a4) were determined. As illustrated in Fig. 7A-B, the mRNA expression levels of transporters in optimized iHep cells were increased significantly compared with the naïve cells.

Protein expression levels of polarized efflux transporters (Bsep, Mrp2, P-gp, Bcrp) were revealed by confocal laser microscopy. As shown in Fig. 7C, similar to SCMH, P-gp, Mrp2, Bcrp and Bsep polarization could be observed in the optimized iHep cells, which indicated the maturation of the hepatocellular efflux system. Furthermore, typical fluorescence images showed that optimized iHep cells could excrete CDF into the canaliculi structures, which is strong evidence for the excretion function of Bsep and Mrp2 (Fig. 7D). These results suggest that optimized iHep cells could form branched canaliculi in vitro and exhibit an excretory function, providing the potential for drug hepatobiliary excretion evaluation.

Drug intrinsic biliary clearance mediated by drug transporters in optimized iHep cells

The capacity for drug disposition in optimized iHep cells was evaluated according to the BEI and $\mathrm{CL}_{\mathrm{b}, \text { int }}$ of selected compounds. As presented in Table 3, the BEI values of DPDPE, d8-TCA, rosuvastatin and methotrexate were significantly increased in optimized iHep cells (BEI values were more than $10 \%$ ), while the efflux amount into bile canaliculi in naïve iHep cells was negligible (BEI value was less than 5\%); furthermore, the efflux amount was almost impossible to calculate $\mathrm{CL}_{\mathrm{b}, \text { int }}$ in naïve iHep cells (Table 3). The calculated $\mathrm{CL}_{\mathrm{b}, \mathrm{int}}$ of selected compounds in optimized iHep or naïve iHep cells correlated with that in SCMHs. The correlation coefficient values $\left(r^{2}\right)$ were 0.984 and 0.655 , respectively (Fig. 8).

Prediction of drug-induced cholestasis mediated by bile acid transporter inhibition in optimized iHep cells

The influence of exposure to compounds that induced cholestasis on the d8-TCA BEI was evaluated in optimized iHep cells. As shown in Fig. 9, the BEI of d8-TCA in optimized 


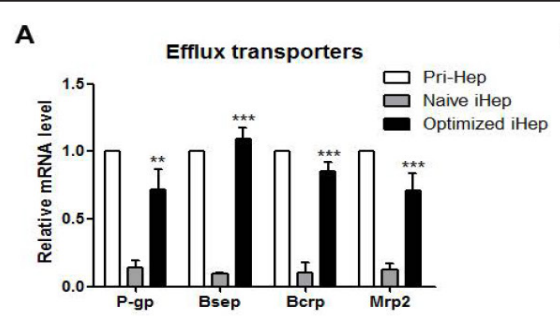

B

C

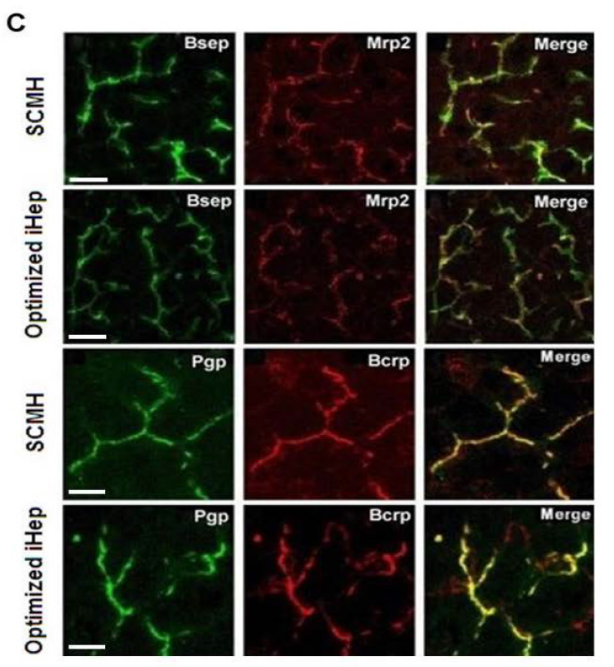

$\mathbf{D}_{\text {SCMH }}$

Naive iHep
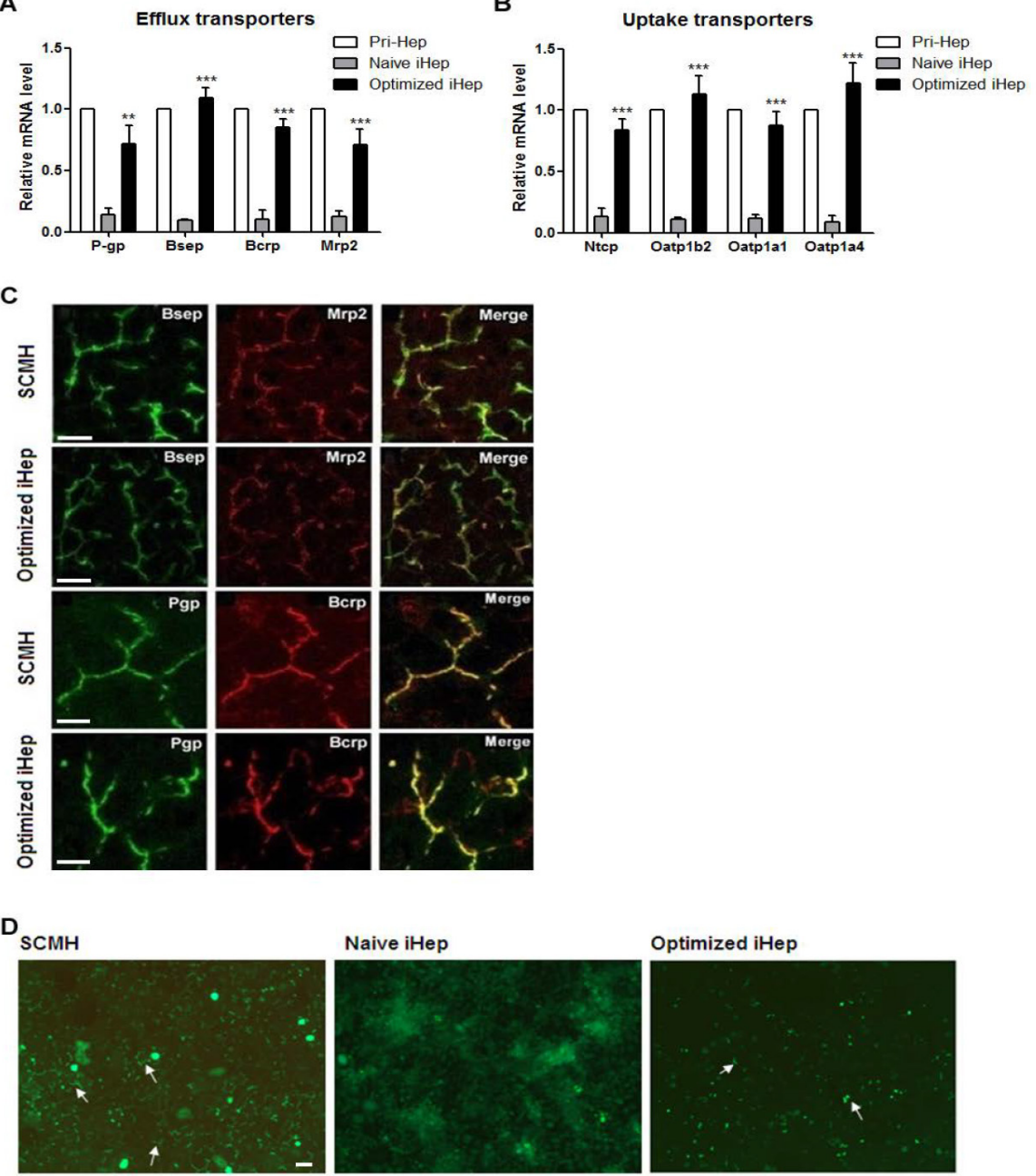

Optimized iHep

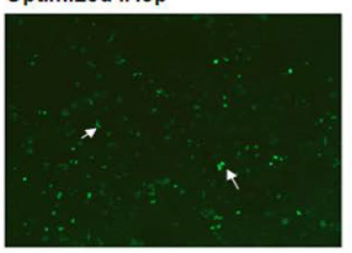

Fig. 7. Transporter expression after application of the optimization strategy. Hepatic mRNA expression levels of efflux and uptake transporters in iHep cells after optimization are shown in (A) and (B), respectively. Optimization consisted of culturing $\mathrm{Hnf} 4 \alpha$-transduced iHep cells in serum-free medium containing cAMP 5 $\mu \mathrm{M}, \mathrm{PB} 50 \mu \mathrm{M}$, TCA $20 \mu \mathrm{M}$ in sandwich configuration. Data are normalized to $\beta$-actin mRNA and are presented as the means \pm SD of three independent experiments. (C) Representative confocal images of Bsep, Mrp2, Pgp and Bcrp in SCMHs and optimized iHep cells. Co-localization (yellow) is indicated in the panels. (D) The formation of bile canaliculi networks is observed in iHep (naïve and optimized) cells and SCMHs. Cells were incubated with $5 \mu \mathrm{M}$ CDF for $10 \mathrm{~min}$. Panels were obtained by fluorescent microscopy. Scale bars, $50 \mu \mathrm{m}$. $* \mathrm{P}<0.05,{ }^{* *} \mathrm{P}<0.01$, and ${ }^{* * *} \mathrm{P}<0.001$ compared to naïve iHep cells.

Table 3. The in vitro biliary excretion capacities of selected compounds in SCMH and iHep cells (naïve and optimized). ${ }^{*} \mathrm{P}<0.05,{ }^{* *} \mathrm{P}<0.01$, and ${ }^{* * *} \mathrm{P}<0.001$ compared to naïve iHep cells

\begin{tabular}{|c|c|c|c|c|c|c|c|c|}
\hline \multirow[t]{2}{*}{ Group } & \multicolumn{2}{|c|}{ DPDPE } & \multicolumn{2}{|c|}{ D8-TCA } & \multicolumn{2}{|c|}{ Rosuvastatin } & \multicolumn{2}{|c|}{ Methotrexate } \\
\hline & BEI (\%) & $\begin{array}{c}\mathrm{CL} b \text {,int } \\
\text { ( } \mu \mathrm{L} / \mathrm{min} \mathrm{mg} \\
\text { protein) }\end{array}$ & BEI (\%) & $\begin{array}{c}\text { CLb,int } \\
\text { ( } \mu \mathrm{L} / \mathrm{min} \mathrm{mg} \\
\text { protein) }\end{array}$ & BEI (\%) & $\begin{array}{c}\mathrm{CL} b \text {,int } \\
(\mu \mathrm{L} / \mathrm{min} \mathrm{mg} \\
\text { protein) }\end{array}$ & BEI (\%) & $\begin{array}{c}C L b, \text { int } \\
\text { ( } \mu \mathrm{L} / \mathrm{min} \mathrm{mg} \\
\text { protein) }\end{array}$ \\
\hline $\mathrm{SCMH}$ & $29.79 \pm 2.26^{*}$ & $0.29 \pm 0.02^{* *}$ & $26.87 \pm 2.58^{*}$ & $0.20 \pm 0.01^{\text {** }}$ & $26.13 \pm 2.41^{*}$ & $0.14 \pm 0.01^{* *}$ & $33.08 \pm 3.06^{*}$ & $0.20 \pm 0.02^{* 4}$ \\
\hline Naïve iHep & $4.14 \pm 1.01$ & $0.043 \pm 0.01$ & $3.17 \pm 0.55$ & $0.029 \pm 0.01$ & $5.14 \pm 1.31$ & $0.043 \pm 0.01$ & $4.33 \pm 1.67$ & $0.039 \pm 0.02$ \\
\hline Optimized iHep & $11.58 \pm 2.92^{*}$ & $0.17 \pm 0.09^{*}$ & $12.34 \pm 1.72^{*}$ & $0.12 \pm 0.01$ & $12.52 \pm 1.60^{*}$ & $0.092 \pm 0.01^{* *}$ & $13.05 \pm 2.11^{*}$ & $0.107 \pm 0.01 *$ \\
\hline
\end{tabular}

iHep cells was significantly reduced after cholestatic drug treatment. The BEI percentage of d8-TCA varied between $7 \%$ in the rifampicin treatment group to $60 \%$ in the troglitazone 
Fig. 8. Transporter function after the optimization strategy. Naïve and optimized iHep cells' biliary clearance (CLb,int) were compared with SCMH. The correlation of test compound CLb,int between SCMHs and iHep cells (naïve and optimized) is shown. Each point represents the mean of two independent experiments.

Fig. 9. Effect of cholestatic drugs on d8-TCA efflux in optimized iHep cells and SCMHs. Optimized iHep cells or SCMHs were treated with d8-TCA $(2.5 \mu \mathrm{M})$ alone or in combination with troglitazone $(10 \mu \mathrm{M})$, bosentan $(30 \mu \mathrm{M})$, chlorpromazine $(150 \mu \mathrm{M})$, rifampicin $(30 \mu \mathrm{M})$, and omeprazole $(100 \mu \mathrm{M})$ for $15 \mathrm{~min}$. The BEI of d8-TCA indicated d8-TCA efflux capacity. Cells treated d8-TCA alone was the control group. The values are expressed as percentages relative to control. Data are the means \pm SD of three independent experiments.
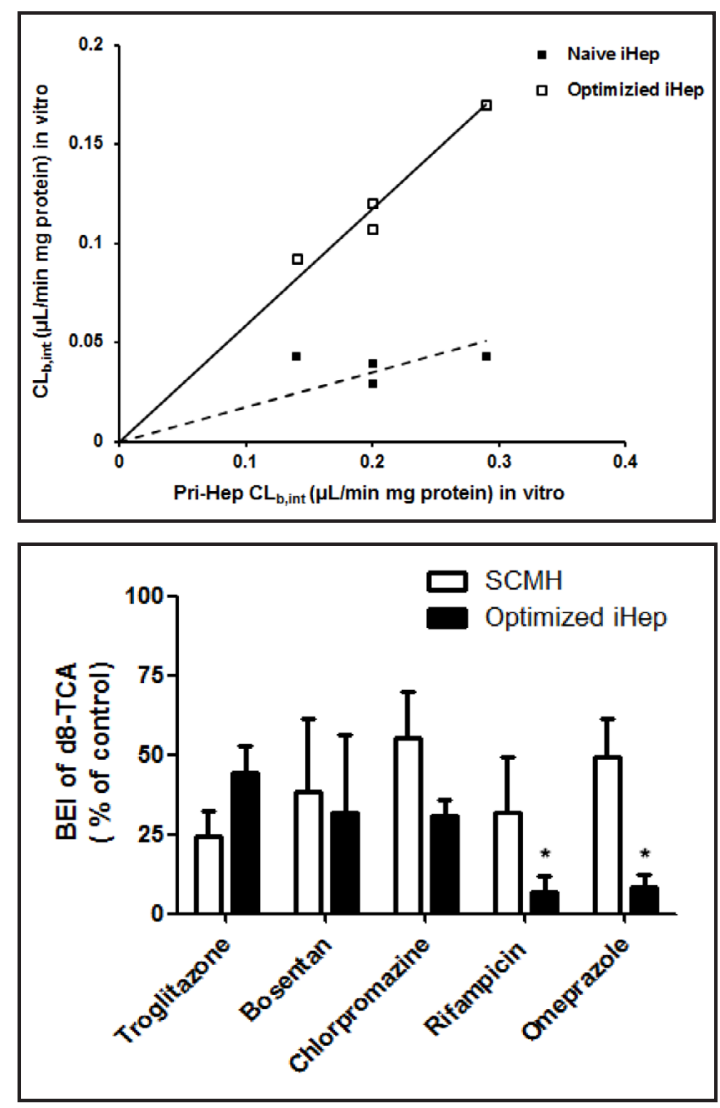

treatment group in optimized iHep cells. The inhibition tendency was similar to that seen in SCMHs (Fig. 9).

\section{Discussion}

Hepatocytes-like cells can be produced by the differentiation of ES or iPS cells, which have progressed considerably over the years [25]. However, procedural complexity and high cost have limited their application, especially in drug screening and clinical therapy [26, 27]. Epigenetic reprogramming highlights a method for direct induction of hepatocyte-like cells without the requirement of ES cells or iPS cells [14, 28], but it is not clear whether this novel cell model can be used to evaluate and predict drug disposition and toxicity. Transporter expression and function are essential for xenobiotic hepatobiliary disposition and bile acid circulation in the liver [29]. In this study, we firstly characterized the expression levels and function of major transporters in novel iHep cells. Our results showed that the mRNA expression profile and membrane localization of uptake and efflux transporters were both weak in naïve iHep cells compared to SCMH cells (Fig. 1A-B). In addition, biliary CLF excretion was very low in naïve iHep cells, which reflected the weak function of Bsep (an important bile acid transporter) (Fig. 1D). This finding suggests that the novel derived iHep cells from fibroblasts were still far away from mature hepatocytes.

Many attempts were made to improve the transporters' expression and function of naïve iHep cells. Hnf $4 \alpha$, one of the nuclear receptors in the liver, was reported to be essential for liver differentiation and development [30,31]. According to Huang's study, the Hnf $4 \alpha$ expression level was increased after Hnf1 $\alpha$ transfection in iHep cells [14]. However, it seems that the induction was transient, and we could not detect enough $\mathrm{Hnf} 4 \alpha$ after several passages (data not shown). After Hnf4 $\alpha$ overexpression in naïve iHep cells, the expression levels of mostly efflux and uptake transporters were significantly improved, especially those 
responsible for bile acid transport (Fig. 2B). Ntcp and Bsep are known as the key transporters for hepatic uptake and biliary secretion of bile salts [32,33]. Ntcp is strongly regulated and induced by Hnf4 $\alpha$ in mice [34]. After Hnf4 $\alpha$ transfection, the Ntcp, Bsep mRNA levels in iHep cells could reach $60 \%$ to $70 \%$ of the levels in primary mouse hepatocytes.

Previously, it was reported that certain small molecules could modulate cell phenotypes $[35,36]$ and are able to induce cell differentiation and to regulate cell maturation through the activation of developmental signaling pathways [37,38]. Therefore, the effects of cAMP, 3-MC, PB, TCA, and VPA on drug transporters in iHep cells were investigated. The expression of efflux and uptake transporters was improved after cAMP, PB and TCA treatment (Figs. 3-4). Surprisingly, VPA, a histone deacetylase inhibitor, which was often employed to promote iPS or ES cell differentiation [39-41], had little effect on transporter expression in naïve iHep cells. This mechanism remains to be further studied.

The expression of nuclear receptors and transcription factors was also assessed in iHep cells. Pxr is the main xeno-sensor regulating gene and plays a key role in the regulation of several major drug transporters, such as P-gp and Mrp2 [42, 43]. In our studies, the Pxr pathway was activated in iHep cells after cAMP, PB and TCA treatment, which is consistent with the up-regulation of efflux transporters (P-gp, Mrp2 and Bcrp). The up-regulation of Oatp1s in iHep cells after treatment may be attributed to Fxr activation [44]. TCA treatment strongly activated Fxr, which was regarded as a feedback regulation of bile acid synthesis [45]. After Fxr activation, Bsep is generally up-regulated and Ntcp is down-regulated in hepatocytes $[5,46]$. However, Ntcp and Bsep expression levels were both up-regulated in iHep cells after TCA treatment, which suggests that there may be more than one regulatory pathway for bile acid transporters in iHep cells. For example, the nuclear receptor Car, another xenobiotic sensor, contributes to iHep cell maturation, as Car regulates downstream genes involved in the exogenous molecules' and bile acids' hydroxylation, conjugation, and excretion $[47,48]$. With regard to the transcription factor, our results demonstrated that Nrf2 was up-regulated in iHep cells (Fig. 5D), which is a positive regulator of the expression of drug transporters such as Mrp2 and Bsep [49]. Collectively, it was determined that several key nuclear receptors and factors were activated and induced by either $\mathrm{Hnf} 4 \alpha$ transfection or the small molecule agonists, which was beneficial for hepatic transporter expression and polarization in iHep cells. In addition, the sandwich culture configuration and the serum-free culture medium conditions improved iHep cell differentiation and enhanced transporter polarization as well. Under these conditions, the functional transporters were observed, as indicated by the increased BEI of CLF and rosuvastatin (Fig. 6A-B). However, the functional levels of drug transporters were still much lower than those in primary mouse hepatocytes.

Based on our studies, a novel culture strategy was proposed and successfully employed after the comprehensive investigation of naïve iHep cells. The optimized iHep cells displayed proper localizations of efflux and uptake transporters, which were very similar to those of primary hepatocytes (Fig. 7A-C). In addition, the optimized iHep cells showed formation of canalicular structures, as demonstrated by the fluorescence substrates (Fig. 7D), exhibiting essential hepatic transporter function.

One of the most valuable applications of primary hepatocytes is to evaluate drug biliary excretion $[4,50]$. Here, we determined multiple transporter substrates' hepatobiliary disposition in the optimized iHep cells and compared that with primary hepatocytes. As shown in Table 3, the BEI values of DPDPE, rosuvastatin, MTX and d8-TCA were greater than $10 \%$, indicating the moderate capacities of biliary secretion in optimized iHep cells. Furthermore, the in vitro $\mathrm{CL}_{\mathrm{b} \text {,int }}$ values of the selected drugs/compounds in optimized iHep cells correlated well with those in mouse primary hepatocytes $\left(r^{2}=0.984\right)$, whereas no correlation was observed between the naïve iHep cells and the mouse primary hepatocytes $\left(r^{2}=0.655\right)$ (Fig. 8). These results imply that the optimized iHep cells have a potential capacity to evaluate the hepatobiliary disposition of drug candidates and are a promising substitute model for primary hepatocytes.

Cholestasis represents a frequent manifestation of drug-induced liver injury (DILI) in many cases and is mostly due to Bsep inhibition [51] and alterations in the hepatobiliary KARGER 


\begin{tabular}{|c|c|c|}
\hline Cellular Physiology & Cell Physiol Biochem 2016;38:1815-1830 & \\
\hline and Biochemistry & $\begin{array}{l}\text { DoI: } 10.1159 / 000443120 \\
\text { Published online: May 09, } 2016\end{array}$ & $\begin{array}{l}\text { (0) } 2016 \mathrm{~S} \text {. Karger AG, Basel } \\
\text { www.karger.com/cpb }\end{array}$ \\
\hline
\end{tabular}

transporter system [52]. Using the optimized iHep cells, we investigated the effects of selected drugs on bile acid transportation. The BEI of d8-TCA was significantly decreased after drug treatment, which suggested Bsep function was inhibited in optimized iHep cells (Fig. 9). The inhibition tendencies of optimized iHep cells and primary hepatocytes were very close. These results show that the optimized iHep cells could be successfully used to identify drug candidate cholestasis risk.

In conclusion, our findings suggest that this novel iHep model has the potential and capacity to be used to screen drug candidates that may induce hepatotoxicity by interfering with bile acid hepatobiliary disposition, especially if they can inhibit Ntcp and Bsep functions. A novel optimization strategy highlights the future direction of human somatic cell reprogramming into human induced hepatocyte-like cells and potential clinical applications due to their unlimited availability. Actually, based on our work here, we have recently successfully developed human-origin iHep cells [53], which could be used to identify potential species differences in the near future. The optimized hepatocyte-like cells could be utilized in the pharmaceutical industry or even in clinical applications due to their welldeveloped hepatobiliary disposition capacity and unlimited availability.

\section{Acknowledgments}

This work was supported by the National Natural Science Foundation of China (Grant Nos 81302836 and 81573499) and the National High Technology Research and Development Program of China (Grant No 2013AA032202).

\section{Disclosure Statement}

The authors declare that there are no conflicts of interest.

\section{References}

1 Rosen MB, Das KP, Wood CR, Wolf CJ, Abbott BD, Lau C: Evaluation of perfluoroalkyl acid activity using primary mouse and human hepatocytes. Toxicology 2013;308:129-137.

2 Sahi J, Grepper S, Smith C: Hepatocytes as a tool in drug metabolism, transport and safety evaluations in drug discovery. Curr Drug Discov Technol 2010;7:188-198.

3 Tuschl G, Lauer B, Mueller SO: Primary hepatocytes as a model to analyze species-specific toxicity and drug metabolism. Expert Opin Drug Metab Toxicol 2008;4:855-870.

4 Ramboer E, Vanhaecke T, Rogiers V, Vinken M: Primary hepatocyte cultures as prominent in vitro tools to study hepatic drug transporters. Drug Metab Rev 2013;45:196-217.

5 International Transporter C, Giacomini KM, Huang SM, Tweedie DJ, Benet LZ, Brouwer KL, Chu X, Dahlin A, Evers R, Fischer V, Hillgren KM, Hoffmaster KA, Ishikawa T, Keppler D, Kim RB, Lee CA, Niemi M, Polli JW, Sugiyama Y, Swaan PW, Ware JA, Wright SH, Yee SW, Zamek-Gliszczynski MJ, Zhang L: Membrane transporters in drug development. Nat Rev Drug Discov 2010;9:215-236.

6 Li P, Wang GJ, Robertson TA, Roberts MS: Liver transporters in hepatic drug disposition: an update. Curr Drug Metab 2009;10:482-498.

7 Funk C: The role of hepatic transporters in drug elimination. Expert Opin Drug Metab Toxicol 2008;4:363379.

8 Yildirimman R, Brolen G, Vilardell M, Eriksson G, Synnergren J, Gmuender H, Kamburov A, IngelmanSundberg M, Castell J, Lahoz A, Kleinjans J, van Delft J, Bjorquist P, Herwig R: Human embryonic stem cell derived hepatocyte-like cells as a tool for in vitro hazard assessment of chemical carcinogenicity. Toxicol Sci 2011;124:278-290.

9 Schwartz RE, Fleming HE, Khetani SR, Bhatia SN: Pluripotent stem cell-derived hepatocyte-like cells. Biotechnol Adv 2014;32:504-513. 


\section{Cellular Physiology Cell Physiol Biochem 2016;38:1815-1830 \begin{tabular}{l|l} 
DOI: 10.1159/000443120 & (C) 2016 S. Karger AG, Basel
\end{tabular} and Biochemistry Published online: May 09, $2016 \quad$ www.karger.com/cpb \\ Wu et al.: Optimized Hepatocyte-Like Cells from Mouse Fibroblasts}

10 Bi Y, He Y, Huang J, Su Y, Zhu GH, Wang Y, Qiao M, Zhang BQ, Zhang H, Wang Z, Liu W, Cui J, Kang Q, Zhang Z, Deng Y, Li R, Zhang Q, Yang K, Luu HH, Haydon RC, He TC, Tang N: Functional characteristics of reversibly immortalized hepatic progenitor cells derived from mouse embryonic liver. Cell Physiol Biochem 2014;34:1318-1338.

11 Xie H, Ye M, Feng R, Graf T: Stepwise reprogramming of B cells into macrophages. Cell 2004;117:663-676.

12 Vierbuchen T, Ostermeier A, Pang ZP, Kokubu Y, Sudhof TC, Wernig M: Direct conversion of fibroblasts to functional neurons by defined factors. Nature 2010;463:1035-1041.

13 Ieda M, Fu JD, Delgado-Olguin P, Vedantham V, Hayashi Y, Bruneau BG, Srivastava D: Direct reprogramming of fibroblasts into functional cardiomyocytes by defined factors. Cell 2010;142:375-386.

14 Huang P, He Z, Ji S, Sun H, Xiang D, Liu C, Hu Y, Wang X, Hui L: Induction of functional hepatocyte-like cells from mouse fibroblasts by defined factors. Nature 2011;475:386-389.

15 Greenhough S, Medine CN, Hay DC: Pluripotent stem cell derived hepatocyte like cells and their potential in toxicity screening. Toxicology 2010;278:250-255.

16 Guguen-Guillouzo C, Corlu A, Guillouzo A: Stem cell-derived hepatocytes and their use in toxicology. Toxicology 2010;270:3-9.

17 Li W-C, Ralphs K, Tosh D: Isolation and culture of adult mouse hepatocytes; in (Ward A, and Tosh D, eds) Mouse Cell Culture. Humana Press, 2010, vol 633, pp.185-196.

18 Yan GZ, Brouwer KL, Pollack GM, Wang MZ, Tidwell RR, Hall JE, Paine MF: Mechanisms underlying differences in systemic exposure of structurally similar active metabolites: comparison of two preclinical hepatic models. J Pharmacol Exp Ther 2011;337:503-512.

19 Pan GY, Boiselle C, Wang JL: Assessment of biliary clearance in early drug discovery using sandwichcultured hepatocyte model. J Pharm Sci 2012;101:1898-1908.

20 Stieger B, Hagenbuch B, Landmann L, Höchli M, Schroeder A, Meier P: In situ localization of the hepatocytic $\mathrm{Na}+$ /Taurocholate cotransporting polypeptide in rat liver. Gastroenterology 1994;107:1781.

21 Marion TL, Perry CH, St Claire RL, 3rd, Yue W, Brouwer KL: Differential disposition of chenodeoxycholic acid versus taurocholic acid in response to acute troglitazone exposure in rat hepatocytes. Toxicol Sci 2011;120:371-380.

22 Swift B, Brouwer KL: Influence of seeding density and extracellular matrix on bile Acid transport and mrp4 expression in sandwich-cultured mouse hepatocytes. Mol Pharm 2010;7:491-500.

23 Wu ZT, Qi XM, Sheng JJ, Ma LL, Ni X, Ren J, Huang CG, Pan GY: Timosaponin A3 induces hepatotoxicity in rats through inducing oxidative stress and down-regulating bile acid transporters. Acta Pharmacol Sin 2014;35:1188-1198.

24 Liu X, Chism JP, LeCluyse EL, Brouwer KR, Brouwer KLR: Correlation of biliary excretion in sandwichcultured rat hepatocytes and in vivo in rats. Drug Metab Dispos 1999;27:637-644.

25 Wilkening S, Stahl F, Bader A: Comparison of primary human hepatocytes and hepatoma cell line HepG2 with regard to their biotransformation properties. Drug Metab Dispos 2003;31:1035-1042.

26 Jensen J, Hyllner J, Björquist P: Human embryonic stem cell technologies and drug discovery. J Cell Physiol 2009;219:513-519.

27 Yu J, Su X, Zhu C, Pan Q, Yang J, Ma J, Shen L, Cao H, Li L: GFP labeling and hepatic differentiation potential of human placenta-derived mesenchymal stem cells. Cell Physiol Biochem 2015;35:2299-2308.

28 Sekiya S, Suzuki A: Direct conversion of mouse fibroblasts to hepatocyte-like cells by defined factors. Nature 2011;475:390-393.

29 Lundquist P, Englund G, Skogastierna C, Loof J, Johansson J, Hoogstraate J, Afzelius L, Andersson TB: Functional ATP-binding cassette drug efflux transporters in isolated human and rat hepatocytes significantly affect assessment of drug disposition. Drug Metab Dispos 2014;42:448-458.

30 Watt AJ, Garrison WD, Duncan SA: HNF4: a central regulator of hepatocyte differentiation and function. Hepatology 2003;37:1249-1253.

31 Parviz F, Matullo C, Garrison WD, Savatski L, Adamson JW, Ning G, Kaestner KH, Rossi JM, Zaret KS, Duncan SA: Hepatocyte nuclear factor 4alpha controls the development of a hepatic epithelium and liver morphogenesis. Nat Genet 2003;34:292-296.

32 Hagenbuch B, Meier PJ: Molecular cloning, chromosomal localization, and functional characterization of a human liver Na+/bile acid cotransporter. J Clin Invest 1994;93:1326-1331.

33 Hayashi H, Sugiyama Y: Bile salt export pump (BSEP/ABCB11): trafficking and sorting disturbances. Curr Mol Pharmacol 2013;6:95-103. 


\section{Cellular Physiology Cell Physiol Biochem 2016;38:1815-1830 \begin{tabular}{l|l|l}
\hline DOI: 10.1159/000443120 & (C) 2016 S. Karger AG, Basel
\end{tabular} and Biochemistry Published online: May 09, 2016 \\ Wu et al.: Optimized Hepatocyte-Like Cells from Mouse Fibroblasts}

34 Geier A, Martin IV, Dietrich CG, Balasubramaniyan N, Strauch S, Suchy FJ, Gartung C, Trautwein C, Ananthanarayanan M: Hepatocyte nuclear factor-4alpha is a central transactivator of the mouse Ntcp gene. Am J Physiol Gastrointest Liver Physiol 2008;295:G226-233.

35 Shan J, Schwartz RE, Ross NT, Logan DJ, Thomas D, Duncan SA, North TE, Goessling W, Carpenter AE, Bhatia SN: Identification of small molecules for human hepatocyte expansion and iPS differentiation. Nat Chem Biol 2013;9:514-520.

36 Borowiak M, Maehr R, Chen S, Chen AE, Tang W, Fox JL, Schreiber SL, Melton DA: Small molecules efficiently direct endodermal differentiation of mouse and human embryonic stem cells. Cell Stem Cell 2009;4:348358.

37 Goessling W, North TE, Loewer S, Lord AM, Lee S, Stoick-Cooper CL, Weidinger G, Puder M, Daley GQ, Moon RT, Zon LI: Genetic interaction of PGE2 and Wnt signaling regulates developmental specification of stem cells and regeneration. Cell 2009;136:1136-1147.

38 Ogawa S, Surapisitchat J, Virtanen C, Ogawa M, Niapour M, Sugamori KS, Wang S, Tamblyn L, Guillemette C, Hoffmann E, Zhao B, Strom S, Laposa RR, Tyndale RF, Grant DM, Keller G: Three-dimensional culture and cAMP signaling promote the maturation of human pluripotent stem cell-derived hepatocytes. Development 2013;140:3285-3296.

39 Dong X, Pan R, Zhang H, Yang C, Shao J, Xiang L: Modification of histone acetylation facilitates hepatic differentiation of human bone marrow mesenchymal stem cells. PLoS One 2013;8:e63405.

40 Dong XJ, Zhang GR, Zhou QJ, Pan RL, Chen Y, Xiang LX, Shao JZ: Direct hepatic differentiation of mouse embryonic stem cells induced by valproic acid and cytokines. World J Gastroenterol 2009;15:5165-5175.

41 Kondo Y, Iwao T, Yoshihashi S, Mimori K, Ogihara R, Nagata K, Kurose K, Saito M, Niwa T, Suzuki T, Miyata N, Ohmori S, Nakamura K, Matsunaga T: Histone deacetylase inhibitor valproic acid promotes the differentiation of human induced pluripotent stem cells into hepatocyte-like cells. PLoS One 2014;9:e104010.

42 Gahir SS, Piquette-Miller M: Gestational and pregnane X receptor-mediated regulation of placental ATPbinding cassette drug transporters in mice. Drug Metab Dispos 2011;39:465-471.

43 Kliewer SA, Goodwin B, Willson TM: The nuclear pregnane X receptor: a key regulator of xenobiotic metabolism. Endocr Rev 2002;23:687-702.

44 Meyer Zu Schwabedissen HE, Bottcher K, Chaudhry A, Kroemer HK, Schuetz EG, Kim RB: Liver X receptor alpha and farnesoid $X$ receptor are major transcriptional regulators of OATP1B1. Hepatology 2010;52:1797-1807.

45 Ellis E, Axelson M, Abrahamsson A, Eggertsen G, Thörne A, Nowak G, Ericzon BG, Björkhem I, Einarsson C: Feedback regulation of bile acid synthesis in primary human hepatocytes: evidence that CDCA is the strongest inhibitor. Hepatology 2007;38:930-938.

46 Halilbasic E, Claudel T, Trauner M: Bile acid transporters and regulatory nuclear receptors in the liver and beyond. J Hepatol 2013;58:155-168.

47 Qatanani M, Moore DD: CAR, the continuously advancing receptor, in drug metabolism and disease. Curr Drug Metab 2005;6:329-339.

48 Wei P, Zhang J, Egan-Hafley M, Liang S, Moore DD: The nuclear receptor CAR mediates specific xenobiotic induction of drug metabolism. Nature 2000;407:920-923.

49 Weerachayaphorn J, Cai SY, Soroka CJ, Boyer JL: Nuclear factor erythroid 2-related factor 2 is a positive regulator of human bile salt export pump expression. Hepatology 2009;50:1588-1596.

50 Matsunaga N, Nunoya K, Okada M, Ogawa M, Tamai I: Evaluation of hepatic disposition of paroxetine using sandwich-cultured rat and human hepatocytes. Drug Metab Dispos 2013;41:735-743.

51 Dawson S, Stahl S, Paul N, Barber J, Kenna JG: In vitro inhibition of the bile salt export pump correlates with risk of cholestatic drug-induced liver injury in humans. Drug Metab Dispos 2012;40:130-138.

52 Rodrigues AD, Lai Y, Cvijic ME, Elkin LL, Zvyaga T, Soars MG: Drug-induced perturbations of the bile acid pool, cholestasis, and hepatotoxicity: mechanistic considerations beyond the direct inhibition of the bile salt export pump. Drug Metab Dispos 2014;42:566-574.

53 Huang P, Zhang L, Gao Y, He Z, Yao D, Wu Z, Cen J, Chen X, Liu C, Hu Y, Lai D, Hu Z, Chen L, Zhang Y, Cheng X, Ma X, Pan G, Wang X, Hui L: Direct reprogramming of human fibroblasts to functional and expandable hepatocytes. Cell Stem Cell 2014;14:370-384. 